\title{
Review of spinal pseudomeningoceles and cerebrospinal fluid fistulas
}

\author{
MaRK W. HaWK, M.D., AND KeE D. KiM, M.D. \\ Department of Neurological Surgery, University of California, Davis, Sacramento, California
}

\begin{abstract}
Spinal pseudomeningoceles and cerebrospinal fluid (CSF) fistulas are uncommon extradural collections of CSF that may result from inadvertent tears in the dural-arachnoid layer, traumatic injury, or may be congenital in origin. Most pseudomeningoceles are iatrogenic and occur in the posterior lumbar region following surgery. The true incidence of iatrogenic pseudomeningoceles following laminectomy or discectomy is unknown; however, the authors of several published reports suggest that the incidence of lumbar pseudomeningoceles following laminectomy or discectomy is between $0.07 \%$ and $2 \%$. Pseudomeningoceles are often asymptomatic, but patients may present with recurrence of low-back pain, radiculopathy, subcutaneous swelling, or with symptoms of intracranial hypotension. Very rarely, they present with delayed myelopathy. Although magnetic resonance imaging is the neurodiagnostic study of choice, computerized tomography myelography and radionuclide myelographic study may be helpful diagnostic tools in some cases. Analysis of suspect fluid for $\beta 2$ transferrin may be a useful adjunctive study. Treatment options include close observation for spontaneous resolution, conservative measures such as bed rest and applicaton of an epidural blood patch, lumbar subarachnoid drainage, and definitive surgical repair.
\end{abstract}

\section{KEY WORDS • spinal cord • pseudomeningocele • cerebrospinal fluid fistula • magnetic resonance imaging}

Spinal pseudomeningoceles and CSF fistulas are caused by similar mechanisms and can be considered on a continuum. Because different mechanisms have been used to explain the pathophysiology of pseudomeningoceles, a precise definition is lacking. Most investigators would consider a pseudomeningocele as an extravasated collection of extradural CSF that results from a dural tear. Because the extradural fluid may be contained in an arachnoid-lined membrane or in a fibrous capsule, multiple terms to describe this entity exist. Pseudomeningoceles have, at various times, been referred to as meningocele spurious, false cysts, or pseudocysts..$^{59,67,68}$ Some authors advocate the use of the term "meningocele" because many are found to have arachnoid-like cell linings. ${ }^{76}$ Most authors, however, prefer the term "pseudomeningocele" because, at least initially, the lesion may not be arachnoid lined, and therefore, it is not a true meningocele. If the proper milieu exists, the extradural fluid collection may be reabsorbed and the communication between the intra- and extradural space may cease to exist. Alternatively, a CSF fistula may result if the extradural fluid communicates with another cavity such as the pleura or if a direct communication to the outside exists. Spontaneous spinal CSF leaks have been recently reported, but the cause of this entity remains unclear and will not be discussed in the present review. ${ }^{82,83}$

Abbreviations used in this paper: $\mathrm{CSF}=$ cerebrospinal fluid; $\mathrm{CT}=$ computerized tomography; $\mathrm{LP}=$ lumboperitoneal; $\mathrm{MR}=$ magnetic resonance.

\section{EPIDEMIOLOGICAL CHARACTERISTICS}

The causes of pseudomeningoceles may be classified into three categories: iatrogenic, traumatic, and congenital. ${ }^{59} \mathrm{By}$ far the most common cause is iatrogenic, resulting from inadvertent dural tears during spinal surgery.

\section{Iatrogenic Causes}

The true incidence of iatrogenic lumbar pseudomeningoceles is difficult to ascertain because many remain asymptomatic. The reported incidence of unintended durotomy is anywhere from 0.3 to $13 \%$ and most frequently occurs as a result of lumbar laminectomy. ${ }^{37,48,63,64}$ The higher prevalence of pseudomeningoceles in the lumbar region has been attributed to both the large number of lumbar laminectomies performed in this region and the increased intraspinal CSF pressure in the caudal thecal sac, compared with the cervical and thoracic spine.

In 1947, Swanson and Fincher ${ }^{90}$ reported a postoperative incidence of pseudomeningocele of $0.07 \%$ in a series in which 1700 lumbar laminectomies had been performed. Mayfield ${ }^{55}$ retrospectively reviewed 1408 cases of lumbar laminectomy undertaken between 1971 and 1975 and found a $0.3 \%$ incidence of CSF fistula requiring reoperation and an $0.8 \%$ incidence of pseudomeningocele in symptomatic patients. Prior to the development of CT scanning and MR imaging, myelography was most commonly used to diagnose pseudomeningoceles and CSF fistulas; thus, the true incidence may have been underestimated. In 1983, Teplick, et al., ${ }^{92}$ reported a $2 \%$ incidence 
of pseudomeningocele in 400 postlaminectomy patients who underwent CT scanning for assessment of postoperative low-back pain or radicular symptoms. Although not well documented, the incidence of iatrogenic pseudomeningocele is probably higher in patients in whom surgery or radiotherapy has been undertaken and for those with intradural lesions requiring durotomy. ${ }^{87,100,101}$

In the cervical region, the surgical treatment of ossified posterior longitudinal ligament is associated with a high incidence of pseudomeningocele and CSF fistula formation. ${ }^{21}$ The reported incidence following this operation ranges from 4.5 to $32 \% .{ }^{52,89}$ Cervical laminectomy, discectomy, and corpectomy have also been associated with the development of postoperative pseudomeningoceles. ${ }^{11,25,33}$ Other iatrogenic causes include lumbar puncture and inadvertent dural puncture after placement of an epidural catheter. ${ }^{12,39,49}$

\section{Traumatic Causes}

Trauma-related CSF fistulas and pseudomeningoceles are rarer than iatrogenic lesions. Because only several cases have been reported, the true incidence of CSF fistula and pseudomeningocele following blunt and penetrating injury to the spine is unknown. Injuries to the brachial and lumbosacral plexus resulting from blunt trauma account for the majority of these lesions and result in nerve root pseudomeningoceles. ${ }^{70}$ Because the brachial and lumbosacral plexus are anchored between two mobile parts, any forceful distraction can stretch either of them and result in nerve root avulsion and ultimately the formation of a nerve root pseudomeningocele. Although cervical pseudomeningoceles frequently occur in the absence of fracture, lumbosacral nerve root avulsions are commonly associated with sacral or pelvic fractures. ${ }^{3,15,28}$ Thoracic nerve roots, by contrast, are well protected by the limited mobility of the thoracic spine and only a few cases of blunt trauma-induced thoracic nerve root pseudomeningocele following blunt trauma have been reported..$^{38,65}$

Pseudomeningoceles unrelated to the nerve roots that develop following blunt cervical trauma are even rarer and are usually associated with head injury. A case of a posterior pseudomeningocele associated with atlantoaxial instability following a motor vehicle accident and two cases of retropharyngeal pseudomeningoceles after atlantooccipital dislocation have been reported. ${ }^{51,62}$ There is a high rate of dural tears resulting from thoracolumbar burst fractures with associated laminar fractures, but these lesions rarely progress to a pseudomeningocele or CSF fistula. ${ }^{10}$ In fractures of the thoracic spine, rare cases of pseudomeningoceles have been associated with severe spinal cord injury due to tremendous kinetic forces. ${ }^{13}$ Spinal pleural fistulas that occur following a motor vehicle accident or a gunshot wound to the thoracic region have also been reported. ${ }^{66,99,102}$ Nonmissile penetrating injuries to the neck commonly lead to the dural tears and CSF leaks. Thakur, et al., ${ }^{93}$ have reported a $36 \%$ incidence of CSF leaks associated with nonmissile penetrating injury to the spine (for example, knives, ice picks, bicycle spokes, glass fragments, and screw drivers) in the South African population.

\section{Congenital Causes}

Congenital cysts tend to occur in the thoracic or thoracolumbar region and have been associated with Marfan syndrome and neurofibromatosis. ${ }^{98}$ Pyeritz $^{74}$ concluded that the prevalence of dural ectasia in patients with Marfan syndrome was as high as $67 \%$ but that most are asymptomatic. Dolynechuk, et al., ${ }^{16}$ have noted that sacral protrusion of the thoracic meninges has been associated with neurofibromatosis in $64 \%$ of 98 cases reported since this phenomenon was first described by Pohl ${ }^{71}$ in 1933 . The incidence of actual pseudomeningocele, compared with dural ectasia, in either of these syndromes is thought to be much lower. ${ }^{84}$ Schneider, et al. ${ }^{84}$ have reported a patient with Marfan syndrome who presented with an anterior sacral meningocele. Although postoperative anterior pseudomeningocele has been reported, ${ }^{43}$ anterior pseudomeningocele is usually congenital in origin and is associated with defects in the vertebral bodies.

\section{PATHOPHYSIOLOGICAL CHARACTERISTICS}

Iatrogenic pseudomeningoceles may or may not be associated with an archnoid tear, but a dural tear is necessary for one to form. If the arachnoid is not violated, the arachnoid membrane may subsequently herniate through the dural defect and a CSF-filled arachnoid sac forms. Rinaldi and Peach ${ }^{77}$ found arachnoidal cells within the capsular membrane of pseudomeningoceles and advocated terming these lesions "true meningoceles." Others have contended that the CSF extravasates through a dural-arachnoid tear and into the surrounding soft tissues, eventually leading to an arachnoid-lined, fibrous capsule. ${ }^{59,67}$

The factors that contribute to a persistent communication between the subarachnoid and the extradural spaces have been debated. Teplick, et al., ${ }^{92}$ have suggested that when intact arachnoid herniates into the cyst, the communication is more likely to remain open and form a pseudomeningocele, whereas when an arachnoidal tear occurs, the likelihood of closure of the communication is greater. Tsuji, et al., ${ }^{94}$ have argued that the volume of the leakage was more important; thus, if a CSF leak is small, the fluid is easily absorbed and the lesion is self-limited. Other authors, however, contend that a smaller communication leads to a higher probability of pseudomeningocele formation, because this acts as a ball valve mechanism, allowing a one-way flow of CSF. ${ }^{6} \mathrm{Cobb}$ and Ehni ${ }^{11}$ have lent support to this theory, describing a pseudomeningocele connected to the subarachnoid space through a small channel. The trapped CSF then collects in the traumatized postoperative bed of the paraspinal musculature and an abnormal connective tissue reaction occurs that leads to poor CSF absorption. 6,25

Trauma-induced brachial plexus pseudomeningoceles form by a different mechanism. In brachial plexus nerve root avulsions, the arachnoid and dura that invest the nerve root are torn, and CSF leaks into the perineural soft tissues. A cavity is formed by proliferation and fusion of dura and epineurium. ${ }^{9}$ The cyst is then lined by reformed arachnoid. Retraction of severed nerve root by wallerian degeneration and CSF pulsations may lead to enlargement of the cavity. ${ }^{97}$

Barberá, et al., ${ }^{2}$ reported on a case of trauma-induced lumbosacral nerve root pseudomeningocele and reviewed 16 other cases. They theorized that the junction between the radicular sheath proximal to the ganglion and the dorsal sac is a "locus minor resistentiae" where traction can 
TABLE 1

Signs and symptoms associated with pseudomeningoceles and CSF fistulas

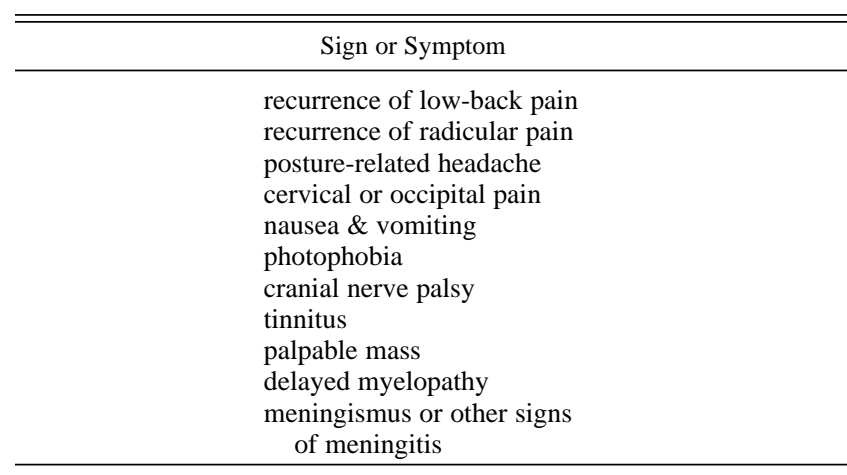

be centered. Weakness at this junction could explain why congenital cysts appear similar to traumatic lesions. Shahinfar and Schechter ${ }^{86}$ have maintained that sectorial defects of the dural sac may occur on a congenital or iatrogenic basis and probably play a role in the cause of cyst formation. As mentioned previously, an increased incidence of pseudomeningocele has been noted in patients with Marfan syndrome, and the cause has been attributed to pulsatile pressure of CSF on a dural membrane that is more elastic than normal.

\section{CLINICAL FEATURES}

Pseudomeningoceles and CSF fistulas may present with a variety of signs and symptoms (Table 1). Most pseudomeningoceles, however, remain asymptomatic. The time interval between the original surgery to the onset of symptoms may range from months to years. ${ }^{59}$ Some pseudomeningoceles may present as a fluctuant mass that enlarges when a patient coughs or sneezes. ${ }^{78}$ (Fig. 1). Palpation in the region of the cyst may cause pain, as was seen in six of six patients with pseudomeningoceles studied by Aldrete and Ghaly. ${ }^{1}$ Cutaneous CSF fistulas are often diagnosed by simple inspection of the wound. If there is a watery discharge that produces a clear halo surrounding a central pink stain, then the fluid is assumed to be CSF.

Patients commonly present with recurrence of preoperative symptoms, including periodic low-back and radicular pain aggravated by straining maneuvers. Radicular motor or sensory loss may be present. ${ }^{1,27,63,76,98}$ The signs and symptoms may materialize as a result of nerve roots that become adherent to the fistulous opening into the pseudomeningocele, or from the movement of the spine causing stretching of the anchored nerve root. ${ }^{76}$ Nerve roots may also herniate into the pseudomeningocele. Straining can cause wedging of the nerve root with subsequent development of sensorimotor radiculopathy. This concept is supported by the findings of several case reports. Hadani, et al. ${ }^{27}$ have reported three cases of nerve root entrapment following laminectomy. Wilkinson ${ }^{98}$ has reported a case of nerve root entrapment within a pseudomeningocele that the author attributed to the patient's delayed onset of radicular signs and symptoms. Conversely, Miller and Elder ${ }^{59}$ have reported a case of nerve root entrapment within a pseudomeningocele, but they be-

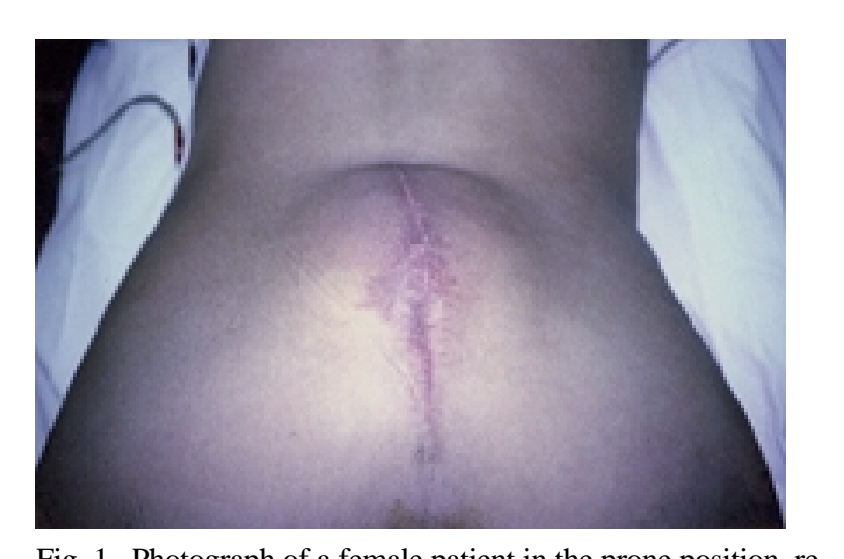

Fig. 1. Photograph of a female patient in the prone position, revealing a large fluctuant mass consistent with a pseudomeningocele in the posterior lumbar location. The patient had previously undergone a procedure in which the spinal cord had been untethered, and she presented 10 days later with a complaint of posturerelated headaches. Examination of her back at that time was unremarkable, and the fluctuant mass did not become obvious until almost 1 month postoperatively.

lieved that the patient's symptoms were unrelated to this finding. Although uncommon, one must be aware that congenital cysts can present with intermittent back and radicular pain and can be confused with other lesions such as herniated discs. ${ }^{98}$

More rarely, a patient may present with progressive or delayed myelopathy following cervical spine surgery. ${ }^{7,11,25}$, 29,30,34 Goodman and Gregorius ${ }^{25}$ have published a case report in which they describe a patient who presented with progressive myelopathy and was found intraoperatively to have spinal cord herniation. They observed the spinal cord periodically bulging into the cyst with each heartbeat and respiration. The authors concluded that myelopathy related to a cervical pseudomeningocele may result from spinal cord herniation (CSF pressure $>$ cyst pressure) or focal cord compression (CSF pressure $<$ cyst pressure). Depending on the location of the lesion, patients with myelopathy may present with a spinal cord syndrome. Horowitz, et al., ${ }^{33}$ have reported a patient who presented with a Brown-Séquard and Horner syndromes caused by the development of a cervicothoracic pseudomeningocele following an anterior cervical discectomy. Patients with pseudomeningoceles may also present with symptoms similar to those seen in those with spontaneous intracranial hypotension, including photophobia, cranial nerve palsies, and tinnitus. ${ }^{5,31}$ Very frequently, posture-related headaches, relieved in a recumbent position, may be present. ${ }^{24}$ Patients may complain of cervical or occipital pain with or without nausea and vomiting while in a standing position. Lastly, patients with unrecognized CSF fistulas may present with signs and symptoms of acute or chronic meningitis. ${ }^{44,60}$

\section{DIAGNOSTIC STUDIES}

Diagnosis by history and physical examination can be augmented by several imaging modalities.

\section{Magnetic Resonance Imaging}

Today, MR imaging is the diagnostic study of choice. 


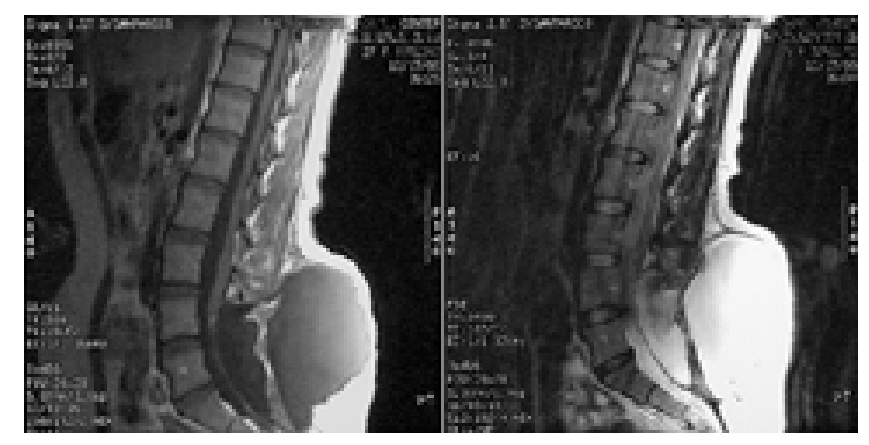

Fig. 2. Sagittal $\mathrm{T}_{1}$ (left) and $\mathrm{T}_{2}$-weighted $\mathrm{MR}$ images obtained of the lumbar spine (same patient as in Fig. 1) demonstrating a large dorsal fluid collection contiguous with the subarachnoid space. Intraoperatively, a pseudomeningocele originating from a small suture hole was observed.

Typically it reveals a region of low signal intensity on $\mathrm{T}_{1}-$ weighted images and high signal intensity on $\mathrm{T}_{2}$-weighted images consistent with CSF $^{34,85}$ (Fig. 2). Magnetic resonance imaging can delineate the location, extent, and internal characteristics of the lesion and may demonstrate its level of communication with the thecal sac. It may also elucidate other associated pathological entities such as spinal cord compression or nerve root entrapment, as well as differentiate pseudomeningoceles from syringomyelia, arachnoiditis, or recurrent tumor. ${ }^{34,46}$ Findings noted in spontaneous intracranial hypotension, including intracranial meningeal enhancement, subdural fluid collections, and caudal displacement of the cerebellar tonsils may also be visualized. ${ }^{82}$

\section{Computerized Tomography Myelography}

Myelography combined with CT scanning may better visualize the location of the pseudomeningocele or fistulous communication relative to a surgical site because of the superior bone imaging quality of CT scanning compared with MR imaging (Fig. 3). Calcified pseudomeningoceles have been reported, ${ }^{80,85,94}$ and erosion into posterior vertebral elements has been documented. ${ }^{46}$ Although Barron ${ }^{4}$ reported a case study of pseudomeningocele with an enhancing capsule, typically there is no contrast enhancement. Delayed CT myelography, in which the scan itself follows intrathecal contrast administration by several hours, may detect a slow-filling pseudomeningocele. ${ }^{46}$ Depending on the location of the pseudomeningocele, the positioning of the patient during the study may need to be modified. In general, however, a supine position allows for adequate delineation of the lesion, because most pseudomeningoceles are posteriorly located..$^{34,53,76}$

\section{Retrograde Radionuclide Myelography}

Retrograde radionuclide myelography has been used to detect chronic dural CSF fistulas. Chronic CSF leaks, as opposed to pseudomeningoceles, may be particularly difficult to detect due to slow leakage and minimal CSF collection. Retrograde radionuclide myelography has been used to detect slow, intermittent leaks after lumbar puncture ${ }^{24,32,73} \mathrm{CSF}$ leaks after spinal surgery and penetrating traumatic injury, ${ }^{50}$ and pleural CSF fistulas. ${ }^{45}$

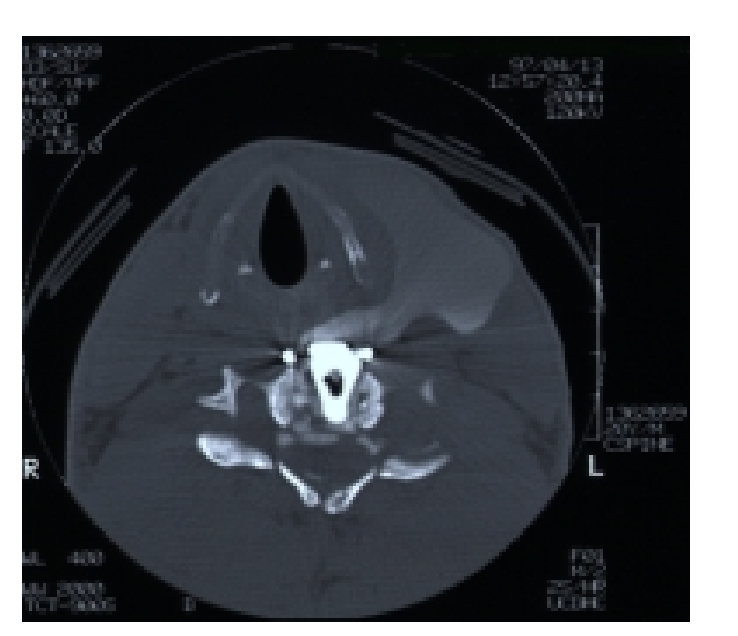

Fig. 3. Computerized tomography myelography demonstrating an anterior cervical pseudomeningocele. This male patient underwent a C-5 corpectomy and anterior cervical arthrodesis in which instrumentation was placed for a C-5 burst fracture and dislocation. Two weeks later he developed a fluctuant mass on the left side of his neck, and axial CT myelography of the cervical spine revealed a large anterior pseudomeningocele. The patient was treated with 7 days of closed lumbar drainage and the lesion resolved.

\section{Myelographic Study}

Trauma-induced nerve root pseudomeningoceles usually appear on myelography as unilateral lesions that vary in size and have irregular contours. ${ }^{9}$ In the cervical region, multiple lesions from C-3 to T-2 are commonly observed. ${ }^{20}$ They readily fill with contrast medium unless communication with the thecal sac has ceased. ${ }^{69,91}$ Frequently, flattening of the lateral margin of the thecal sac, absence of the nerve sheath, and pulsatile leakage of contrast into the extraarachnoidal sacs are visualized. Congenital cysts, as opposed to trauma-induced lesions, tend to be bilateral, small, regular in contour, and often have configurations in the sacral region that appear as clusters of grapes. ${ }^{9}$

\section{Beta 2-Transferrin}

Determining the presence of CSF by measuring the glucose level is an unreliable method. ${ }^{18}$ However, analysis of fluid for $\beta 2$ transferrin is highly sensitive in detecting CSF, because, with rare exception, $\beta 2$ transferrin is found only in the CSF. ${ }^{81} \mathrm{~A}$ small sample size of fluid $(<1 \mathrm{ml})$ is required to detect $\beta 2$ transferrin. Proteins in the fluid are separated by polyacrylamide gel electrophoresis and then transferred electrophoretically onto a nitrocellulose sheet. Using an antibody reaction (immunoblot), banding patterns are analyzed.

The $\beta 2$ isoform arises from $\beta 1$-transferrin through the loss of sialic acid by the action of neuraminidase..$^{75} \mathrm{Be}$ cause neuraminidase is only found in the central nervous system, CSF fluid will have two bands, one representing $\beta 1$ and the other representing $\beta 2$. Serum and other body fluids normally have only one band, represented by $\beta 1$.

False positive results can be caused by alteration in the polypeptide sequence or the carbohydrate moiety of transferrin as a result of genetic variation or other causes. This alters the electrophoretic mobility of the molecule and 
results in mistaking these variants for the CSF isoform. The most common allelic variant of the transferrin gene is TfC. Patients that are homozygous for TfC will have a single band of $\beta 1$. The TfB and TfD allele variants result in proteins with slower and faster mobilities, respectively. Heterozygosity for this allele would then lead to a banding doublet. Thus, non-CSF could be confused with CSF. False interpretation can be avoided by simultaneous comparison of CSF fluid and other body fluid obtained in the same patient. ${ }^{88}$

In individuals who are chronic alcoholics there may be elevated serum concentrations of a partially desialylated transferrin isoform, and an additional intermediate electrophoretic band may appear between $\beta 1$ and $\beta 2 .{ }^{88}$ Increased concentration of the asialo transferrin isoform has also been reported in patients with cirrhosis, neuropsychiatric disorders, rectal cancer, and a rare disorder of glycoprotein metabolism. ${ }^{88}$ Careful attention to the clinical information and comparison of patterns of CSF, serum, and other fluids will allow accurate interpretation of unusual transferrin bands.

\section{TREATMENT}

Close evaluation of preoperative neuroimaging studies, meticulous surgical technique, and liberal use of microscopic magnification will often avert iatrogenic pseudomeningocele and CSF fistula. All available preoperative neurodiagnostic images should be evaluated for evidence of bone defects caused by possible occult spina bifida or previous surgeries. Each Kerrison rongeur bite should be preceded by the necessary dissections to ensure that the dura mater does not come between the footplate and bone. The movement of the drill is directed laterally so that even with a slip a dural tear may be avoided. A cottonoid should cover the exposed dura during the drilling. When a dural tear does occur, every attempt should be made to achieve a water-tight primary closure. This includes extending the laminectomy, if necessary, to gain better exposure to repair the dura, and using loupe magnification or the operating microscope.

Treatment modalities for CSF fistula and pseudomeningoceles include conservative management, placement of an epidural blood patch, lumbar subarachnoid drainage, and surgery. The role of antibiotic therapy has not been well documented for spinal fistulas and pseudomeningocele. However, analysis of reports on the role of antibiotic medication in cranial CSF fistulas and pseudomeningoceles suggests that antibiotic agents do not decrease the short- or long-term incidence of meningitis and have been associated with the development of multidrug resistance. ${ }^{19}$

\section{Conservative Therapy}

Some authors suggest that patients with cervical-region pseudomeningoceles who present without motor or sensory signs may be treated by close observation. ${ }^{33,36}$ Bed rest, particulary in cases of lumbar pseudomeningoceles, is frequently the first step in management. Waisman and Schweppe ${ }^{96}$ have reported successful treatment of eight patients with lumbar-region CSF leaks in whom watertight skin closure was followed by bed rest in the Trendelenburg position. In addition, repeated subcutaneous punctures of the pseudomeningocele were performed in an attempt to reduce a possible ball-valve effect of the pseudomeningocele. The CSF leaks were stopped in all eight patients by 4 weeks posttreatment. Other authors have reported equal success with bed rest in the Trendelenburg position and repetitive cisternal punctures for 2 to 3 days. ${ }^{57}$

\section{Epidural Blood Patch}

Epidural blood patches have been applied successfully to treat patients with postlaminectomy CSF fistulas and pseudomeningoceles. ${ }^{47,54}$ Maycock, et al., ${ }^{54}$ have reported the postlaminectomy case of a patient who underwent surgical reexploration for a CSF fistula; the site of CSF fistula was not found, and the CSF leak continued postoperatively. The CSF fistula was subsequently successfully treated using an epidural blood patch. Clot formation and clot strength are known to increase in the presence of CSF. ${ }^{14,79}$ The injection of blood stops CSF leakage by promoting clot formation over the dural tear and raises extradural tissue pressure relative to subarachnoid pressure, thus decreasing the gradient for CSF efflux..$^{58}$ Because only a few case reports exist in the literature, the success rate of the epidural blood patch in the treatment of CSF fistulas and pseudomeningoceles is unclear.

\section{Closed Lumbar Subarachnoid Drainage}

The first investigators who treated pseudomeningoceles with closed lumbar subarachnoid catheters used teflon or polyethylene catheters. ${ }^{23,26,41,95}$ These catheters, initially designed for epidural use, were complicated by frequent blockage and kinking and were therefore somewhat difficult to use. ${ }^{87}$ In 1992 , Shapiro and Scully ${ }^{87}$ reported the use of silicone lumbar subarachnoid catheters in 39 patients with spinal CSF fistulas and pseudomeningoceles. They reported a $92 \%$ success rate after 7 days of drainage alone. Complications included a $24 \%$ incidence of temporary nerve root irritation that resolved after the drain was removed and a $63 \%$ incidence of transient headaches, nausea, and vomiting. In an earlier report Kitchel, et al., ${ }^{41}$ noted a similar success rate of $90 \%$ in 17 patients treated with 4 days of drainage, but the recurrence rate was higher $(18 \%)$ when compared with that reported by Shapiro and Scully (8\%). The complication rate reported by Kitchel, et al., was similar to that reported by Shapiro and Scully, with a $58 \%$ incidence of headaches, nausea, and vomiting. All patients were successfully treated with adjustment in the rate of CSF drainage, intravenous hydration, and analgesic medication. In each study the authors reported one case of meningitis associated with lumbar subarachnoid drainage and both cases were successfully treated with antibiotic therapy.

McCormack, et al., ${ }^{58}$ reported using an epidural blood patch combined with a brief course of subarachnoid drainage in one patient with lumbar spinal implants. They speculated that CSF diversion alone in patients with spinal implants may not eliminate the pseudomeningocele because the hardware prevents reapproximation of paraspinal tissues. The blood patch procedure obliterates extradural dead space and provides a substrate for clot formation. Dural healing may thus be optimized because CSF diversion and percutaneous blood patch are complementary in decreasing the CSF pressure differences across the dural breech. 
M. W. Hawk and K. D. Kim

\section{Surgical Treatment}

The definitive treatment for CSF fistulas and pseudomeningoceles is reoperation for dural repair. Indications for surgery include failure of conservative measures or progressive radicular or signs and symptoms of myelopathy. For those with a neurological deficit, a delay in surgery may put the patient at risk for further neurological injury. ${ }^{2,27}$ The surgery should begin with adequate lighting, and the skin incision should be generous enough to encompass the area of the leak. Once the pseudomeningocele is visualized, it may be followed deep into the durotomy site. Often the pseudomeningocele may need to be resected to identify the region of interest. The durotomy site is protected with a cottonoid, and any necessary bone resection is performed prior to attempting dural closure to provide adequate room for suturing. Under microscopic magnification, the durotomy site is explored to ensure that nerve root or spinal cord strangulation is not present. In most cases, the dura may be closed primarily, without need of a graft, by using No. 4-0 to 7-0 nonabsorbable sutures on a taper or reverse cutting, half-circle needle. For a large defect, a fascial graft obtained locally or artificial dura may be used to avoid compression of neural elements. ${ }^{22}$ For durotomies that occur in surgically inaccessible areas, such as far-lateral durotomies, a small plug of muscle or fat may be introduced through an intentional medial durotomy and pulled into the defect ${ }^{56}$ (Fig. 4).

If a Valsalva maneuver reveals a persistent leak, a fibrin sealant should be placed over the area of the leak. Analysis of the results obtained in animal studies suggests that fibrin sealant alone can withstand high hydrostatic pressures..$^{8,21,72}$ However, since it remains in situ for only 5 to 7 days, fibrin glue must be supplemented with a dural, muscle, or fat graft placed over the area of the persistent leak. Simply placing Gelfoam or muscle over the dural leak without also applying fibrin glue is ineffective and has been associated with failure to resolve the leak. ${ }^{59,61,76,86}$

Paraspinal muscle and overlying fascia should be closed in at least two layers by using No. 0-gauge monofilament with sutures placed 3 to $4 \mathrm{~mm}$ apart. Surgically placed drains may lead to the persistence of communication between the intra- and extradural space and may serve as a nidus for infection. Therefore, these drains should not be routinely used in the repair of a dural tear or a pseudomeningocele. Postoperatively, patients in whom lumbar defects have been repaired should stay in bed for at least 2 days, although some authors advocate longer periods of bed rest. ${ }^{18}$ We routinely provide a corset brace to those patients in whom a water-tight closure was not attained to minimize the pressure difference across the defect.

Some authors argue that all cervical spine pseudomeningoceles should be treated surgically, ${ }^{53}$ whereas others argue that pseudomeningoceles will resolve with time. Horowitz, et al, ${ }^{33}$ reported a case of an anterior cervical pseudomeningocele that resolved after 3 weeks of expectant observation. In contrast to lumbar defects, patients with repaired cervical defects may ambulate immediately.

The role of an LP shunt in the management of pseudomeningocle and CSF fistulas is not well defined. There are reports of successful management of CSF fistulas ${ }^{17,35,40}$ and a pseudomeningocele ${ }^{42}$ with an LP shunt. However, the placement of permanent hardware should be avoided

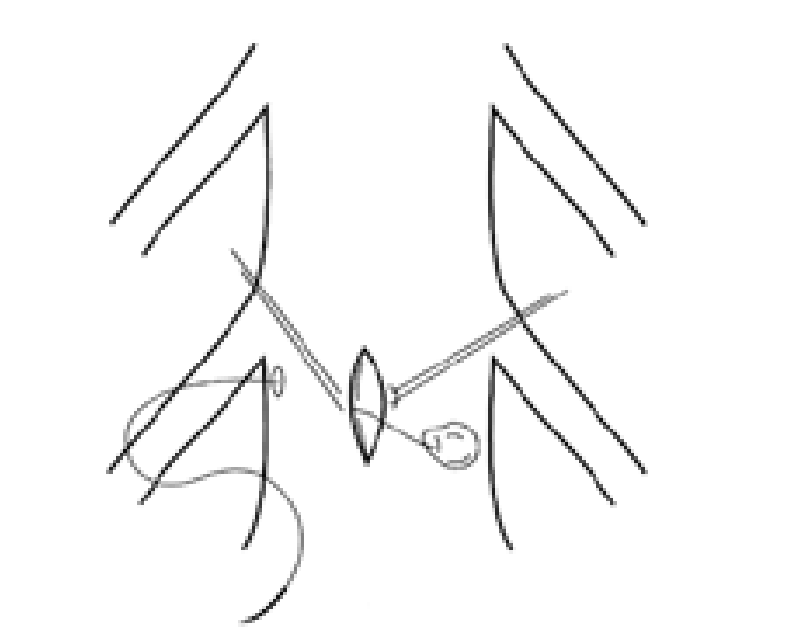

Fig. 4. A schematic drawing of Mayfield's midline durotomy in which a far-lateral dural tear is repaired.

whenever possible and other therapies, including surgical repair, should first be attempted. An LP shunt, in general, should be applied only in those in whom surgical repair failed or in whom surgical repair was not possible due to the location of the defect.

\section{CONCLUSIONS}

Pseudomeningoceles and CSF fistulas are extradural CSF collections uncommonly encountered by the spine surgeons. The great majority are the result of iatrogenic durotomy, usually following lumbar surgery. Many of the lesions remain asymptomatic, but some may present with a range of signs and symptoms including posture-related headaches, localized back pain, radiculopathy, and myelopathy. Although MR imaging is the neurodiagnostic modality of choice, CT myelography and radionuclide myelography may provide useful information in difficult cases. A water-tight closure of the dural defect encountered during surgery is the key to avoiding this complication. When a pseudomeningocele or CSF fistula is encountered, bed rest, an epidural blood patch procedure, or closed lumbar drainage may be attempted. If unsuccessful, direct surgical repair may be necessary, and in rare cases, placement of an LP shunt may be considered.

\section{Acknowledgments}

The authors would like to thank Ms. Martha Robinson and Robert Berman, Ph.D., for their assistance with this manuscript.

\section{References}

1. Aldrete JA, Ghaly R: Postlaminectomy pseudomeningocele. An unsuspected cause of low back pain. Reg Anesth 20:75-79, 1995

2. Barberá J, Broseta J, Argüelles F, et al: Traumatic lumbosacral meningocele. Case report. J Neurosurg 46:536-541, 1977

3. Barnett HG, Connolly ES: Lumbosacral nerve root avulsion: report of a case and review of the literature. J Trauma 15: 532-535, 1975

4. Barron JT: Radiologic case study. Lumbar pseudomeningocele. Orthopedics 13:603, 608-609, 1990

5. Bell WE, Joynt RJ, Sahs AL: Low spinal fluid pressure syndromes. Neurology 10:512-521, 1960 
6. Bhatoe HS: Postoperative lumbar pseudomeningocele. J Indian Med Assoc 93:280-282, 1995

7. Burres KP, Conley FK: Progressive neurological dysfunction secondary to postoperative cervical pseudomeningocele in a C-4 quadriplegic. Case report. J Neurosurg 48:289-291, 1978

8. Cain JE Jr, Rosenthal HG, Broom MJ, et al: Quantification of leakage pressures after durotomy repairs in the canine. Spine 15:969-970, 1990

9. Carlson DH, Hoffman HB: Lumbosacral traumatic meningocele. Report of a case. Neurology 21:174-176, 1971

10. Cammisa F, Eismont F, Green B: Dural laceration occurring with burst fractures and associated laminar fractures. J Bone Joint Surg (Am) 71:1044-1052, 1989

11. Cobb C III, Ehni G: Herniation of the spinal cord into an iatrogenic meningocele. Case report. J Neurosurg 39:533-536, 1973

12. Colletti PM, Siegel ME: Posttraumatic lumbar cerebrospinal fluid leak: detection by retrograde In-111-DTPA myeloscintography. Clin Nucl Med 6:403, 1981

13. Cook DA, Heiner JP, Breed AL: Pseudomeningocele following spinal fracture. A case report and review of the literature. Clin Orthop 247:74-79, 1989

14. Cook MA, Watkins-Pitchford JM: Epidural blood patch: a rapid coagulation response. Anesth Analg 70:567-568, 1990

15. Dobrzaniecki W, Haak E: Meningocele spinalis traumatica spuria. Ann Surg 116:150-153, 1942

16. Dolynchuk KN, Teskey J, West M: Intrathoracic meningocele associated with neurofibromatosis: case report. Neurosurgery 27:485-487, 1990

17. Duthel R, Nuti C, Motuo-Fotso MJ, et al: [Complications of lumboperitoneal shunts. A retrospective study of a series of 195 patients (214 procedures).] Neurochirurgie 42:83-90, 1996 (Fr)

18. Eismont FJ, Wiesel SW, Rothman RH: Treatment of dural tears associated with spinal surgery. J Bone Joint Surg (Am) 63: 1132-1136, 1981

19. Eljamel MS: Antibiotic prophylaxis in unrepaired CSF fistulae. Br J Neurosurg 7:501-505, 1993

20. Epstein BS, Epstein JA: Extrapleural intrathoracic apical traumatic pseudomeningocele. AJR 120:887-892, 1974

21. Epstein NE, Hollingsworth R: Anterior cervical micro-dural repair of cerebrospinal fluid fistula after surgery for ossification of the posterior longitudinal ligament. Technical note. Surg Neurol 52:511-514, 1999

22. Fiala TG, Buchman SR, Muraszko KM: Use of lumbar periosteal turnover flaps in myelomeningocele closure. Neurosurgery 39:522-526, 1996

23. Findler G, Sahar A, Beller A: Continuous lumbar drainage of cerebrospinal fluid in neurosurgical patients. Surg Neurol 8: 455-457, 1977

24. Gass H, Goldstein AS, Ruskin R, et al: Chronic postmyelogram headache. Isotopic demonstration of dural leak and surgical cure. Arch Neurol 25:168-170, 1971

25. Goodman SJ, Gregorius FK: Cervical pseudomeningocele after laminectomy as a cause of progressive myelopathy. Bull LA Neurol Soc 39:121-127, 1974

26. Graf CJ, Gross CE, Beck DW: Complications of spinal drainage in the management of cerebrospinal fluid fistula. J Neurosurg 54:392-395, 1981

27. Hadani M, Findler G, Knoler N, et al: Entrapped lumbar nerve root in pseudomeningocele after laminectomy: report of three cases. Neurosurgery 19:405-407, 1986

28. Hadley MN, Carter LP: Sacral fracture with pseudomeningocele and cerebrospinal fluid fistula: case report and review of the literature. Neurosurgery 26:843-846, 1985

29. Hanakita J, Kinuta Y, Suzuki T: Spinal cord compression due to postoperative cervical pseudomeningocele. Neurosurgery 17: 317-319, 1985

30. Helle TL, Conley FK: Postoperative cervical pseudomenin- gocele as a cause of delayed myelopathy. Neurosurgery 9 314-316, 1981

31. Hochman MS, Naidich TP, Kobetz SA, et al: Spontaneous intracranial hypotension with pachymeningeal enhancement on MRI. Neurology 42:1628-1630, 1992

32. Hofstetter KR, Bjelland JC, Patton DD, et al: Detection of bronchopleural-subarachnoid fistula by radionuclide myelography: case report. J Nucl Med 18:981-983, 1977

33. Horowitz SW, Azar-Kia B, Fine M: Postoperative cervical pseudomeningocele. AJNR 11:784, 1990

34. Hosono N, Yonenobu K, Ono K: Postoperative cervical pseudomeningocele with herniation of the spinal cord. Spine 20: 2147-2150, 1995

35. James HE, Tibbs PA: Diverse clinical applications of percutaneous lumboperitoneal shunts. Neurosurgery 8:39-42, 1981

36. Johnson JP, Lane JM: Traumatic lumbar pseudomeningocele occurring with spina bifida occulta. J Spinal Disord 11:80-83, 1998

37. Jones AA, Stambough JL, Balderston RA, et al: Long-term results of lumbar spine surgery complicated by unintended durotomy. Spine 14:443-446, 1989

38. Kachooie A, Bloch R, Banna M: Post-traumatic dorsal pseudomeningocele. J Can Assoc Radiol 36:262-263, 1985

39. Kadrie H, Driedger AA, McInnis W: Persistent dural cerebrospinal fluid leak shown by retrograde myelography: case report. J Nucl Med 17:797, 1976

40. Katz SS, Savitz MH, Osei C, et al: Successful treatment by lumboperitoneal shunting of a spinal subclavicular fistula following thoracotomy. Neurosurgery 11:795-796, 1982

41. Kitchel SH, Eismont FJ, Green BA: Closed subarachnoid drainage for management of cerebrospinal fluid leakage after an operation on the spine. J Bone Joint Surg (Am) 71:984-987, 1989

42. Kitchen N, Bradford R, Platts A: Occult spinal pseudomeningocele following a trivial injury successfully treated with a lumboperitoneal shunt: a case report. Surg Neurol 38:46-49, 1992

43. Kolawole TM, Patel PJ, Naim-Ur-Rahaman: Post-surgical anterior pseudomeningocele presenting as an abdominal mass. Comput Radiol 11:237-240, 1987

44. Koo J, Adamson R, Wagner FC Jr, et al: A new cause of chronic meningitis: infected lumbar pseudomeningocele. Am J Med 86:103-104, 1989

45. Krasnow AZ, Collier BD, Isitman AT, et al: The use of radionuclide cisternography in the diagnosis of pleural cerebrospinal fluid fistulae. J Nucl Med 30:120-123, 1989

46. Lau KK, Stebnyckyj M, McKenzie A: Post-laminectomy pseudomeningocele: an unusual cause of bone erosion. Aust Radiol 36:262-264, 1992

47. Lauer KK, Haddox JD: Epidural blood patch as treatment for a surgical durocutaneous fistula. J Clin Anesth 4:45-47, 1992

48. Lee KS, Hardy IM II: Postlaminectomy lumbar pseudomeningocele: report of four cases. Neurosurgery 30:111-1114, 1992

49. Lieberman LM, Tourtelotte WW, Newkirk TA: Prolonged postlumbar puncture cerebrospinal fluid leakage from lumbar subarachnoid space demonstrated by radioisotope myelography. Neurology 21:925-929, 1971

50. Liebeskind AL, Herz DA, Rosenthal AD, et al: Radionuclide demonstration of spinal dural leaks. J Nucl Med 4:356-358, 1973

51. Louw JA: Traumatic atlanto-axial pseudomeningocele. A case report. S Afr J Surg 29:26-27, 1991

52. MacDonald RL, Fehlings MG, Tator CH, et al: Multilevel anterior cervical corpectomy and fibular allograft fusion for cervical myelopathy. J Neurosurg 86:990-997, 1997

53. Maiuri F, Corriero G, Giamundo A, et al: Postoperative cervical pseudomeningocele. Neurochirurgia 31:29-31, 1988

54. Maycock NF, Van Essen J, Pfitzner J: Post-laminectomy cerebrospinal fluid fistula treated with epidural blood patch. Spine 19:2223-2225, 1994 
55. Mayfield F: Complications of laminectomy. Clin Neurosurg 23:412-417, 1975

56. Mayfield FH, Kurokawa K: Watertight closure of spinal dura mater. Technical note. J Neurosurg 43:639-640, 1975

57. McCallum JE, Tenicela R, Jannetta PJ: Closed external drainage of cerebrospinal fluid in treatment of postoperative CSF fistula. Surg Forum 24:465-467, 1973

58. McCormack BM, Taylor SL, Heath S, et al: Pseudomeningocele/CSF fistula in a patient with lumbar spinal implants treated with epidural blood patch and a brief course of closed subarachnoid drainage. A case report. Spine 21:2273-2276, 1996

59. Miller PR, Elder FW Jr: Meningeal pseudocysts (meningocele spurius) following laminectomy. Report of ten cases. J Bone Joint Surg (Am) 50:268-276, 1968

60. Nairus JG, Richman JD, Douglas RA: Retroperitoneal pseudomeningocele complicated by meningitis following a lumbar burst fracture. A case report. Spine 21:1090-1093, 1996

61. Nash CL, Kaufman B, Frankel VH: Postsurgical meningeal pseudocysts of the lumbar spine. Clin Orthop 74:167-177, 1971

62. Naso WB, Cure J, Cuddy BG: Retropharyngeal pseudomeningocele after atlanto-occipital dislocation: report of two cases. Neurosurgery 40:1288-1291, 1997

63. O'Connor D, Maskery N, Griffiths WE: Pseudomeningocele nerve root entrapment after lumbar discectomy. Spine 23: 1501-1502, 1998

64. Oppel F, Schramm J, Schirmer M, et al: Results and complicated course after surgery for lumbar disc herniation. Adv Neurosurg 4:36-46, 1977

65. Osaka K, Handa H, Watanabe H: Traumatic intrathoracic meningocele (traumatic subarachnoid-pleural fistula). Surg Neurol 15:137-140, 1981

66. Overton MC III, Hood RM, Farris RG: Traumatic subarachnoid-pleural fistula. Case report. J Thorac Cardiovasc Surg 51:729-731, 1966

67. Pagni CA, Cassinari V, Bernasconi V: Meningocele spurius following hemilaminectomy in a case of lumbar discal hernia. J Neurosurg 18:709-710, 1961

68. Pau A: Postoperative "meningocele spurius." Report of two cases. J Neurosurg Sci 18:150-152, 1974

69. Payne RF, Thompson JLG: Myelography in lumbosacral plexus injury. Br J Radiol 42:840-845, 1969

70. Perrett LV: Traumatic meningoceles. J Coll Radiol Aust 7: 63-67, 1963

71. Pohl R: Meningokele im Brustraum unter dem Bilde eines intrathorakalen Rundschattens. Roentgenpraxis 5:747-749, 1933

72. Pomeranz S, Constantini S, Umansky F: The use of fibrin sealant in cerebrospinal fluid leakage. Neurochirurgia 34: 166-169, 1991

73. Primeau M, Carrier L, Milette PC, et al: Spinal cerebrospinal fluid leak demonstrated by radioisotopic cisternography. Clin Nucl Med 13:701-703, 1988

74. Pyeritz RE: The diagnosis and management of the Marfan syndrome. Am Fam Physician 34:83-94, 1986

75. Reisinger PW, Hochstrasser K: The diagnosis of CSF fistulae on the basis of detection of $\beta$ 2-transferrin by polyacrylamide gel electrophoresis and immunoblotting. J Clin Chem Clin Biochem 27:169-172, 1989

76. Rinaldi I, Hodges TO: Iatrogenic lumbar meningocele: report of three cases. J Neurol Neurosurg Psychiatry 33:484-492, 1970

77. Rinaldi I, Peach WF Jr: Postoperative lumbar meningocele. Report of two cases. J Neurosurg 30:504-507, 1969

78. Rocca A, Turtas S, Pirisi A, et al: Iatrogenic lumbar pseudomeningocele. Zentralbl Neurochir 47:311-315, 1986

79. Rosenberg PH, Heavner JE: In vitro study of the effect of epidural blood patch on leakage through a dural puncture. Anesth Analg 64:501-504, 1985
80. Rosenblum DJ, Derow JR: Spinal extradural cysts, with report of an ossified spinal extradural cyst. AJR 90:1227-1230, 1963

81. Ryall RG, Peacock MK, Simpson DA: Usefulness of $\beta$ 2-transferrin assay in the detection of cerebrospinal fluid leaks following head injury. J Neurosurg 77:737-739, 1992

82. Schievink WI, Morreale VM, Atkinson JLD, et al: Surgical treatment of spontaneous spinal cerebrospinal fluid leaks. J Neurosurg 88:243-246, 1998

83. Schievink WI, Tourje I: Intracranial hypotension without meningeal enhancement on magnetic resonance imaging. Case report. J Neurosurg 92:475-477, 2000

84. Schneider MB, Dittmar S, Boxer RA: Anterior sacral meningocele presenting as a pelvic/abdominal mass in a patient with Marfan syndrome. J Adolescent Health 14:325-328, 1993

85. Schumacher HW, Wassmann H, Podlinski C: Pseudomeningocele of the lumbar spine. Surg Neurol 29:77-78, 1988

86. Shahinfar AH, Schechter MM: Traumatic extradural cysts of the spine. AJR 98:713-719, 1966

87. Shapiro SA, Scully T: Closed continuous drainage of cerebrospinal fluid via a lumbar subarachnoid catheter for treatment or prevention of cranial/spinal cerebrospinal fluid fistula. Neurosurgery 30:241-245, 1992

88. Sloman AJ, Kelly RH: Transferrin allelic variants may cause false positives in the detection of cerebrospinal fluid fistulae. Clin Chem 39: 1444-1445, 1993

89. Smith MD, Bolesta MJ, Leventhal M, et al: Postoperative cerebrospinal-fluid fistula associated with erosion of the dura. Findings after anterior resection of ossification of the posterior longitudinal ligament in the cervical spine. J Bone Joint Surg (Am) 74:270-277, 1992

90. Swanson HS, Fincher EF: Extradural arachnoidal cysts of traumatic origin. J Neurosurg 4:530-538, 1947

91. Taveras JM, Wood EH: Diagnostic Neuroradiology. Baltimore: Williams \& Wilkins, 1964, pp 848-850

92. Teplick JG, Peyster RG, Teplick SK, et al: CT Identification of postlaminectomy pseudomeningocele. AJR 140: 1203-1206, 1983

93. Thakur RC, Khosla VK, Kak VK: Non-missile penetrating injuries of the spine. Acta Neurochir 113:144-148, 1991

94. Tsuji H, Handa N, Handa O, et al: Postlaminectomy ossified extradural pseudocyst. Case report. J Neurosurg 73:785-787, 1990

95. Vourch G: Continuous cerebrospinal fluid drainage by indwelling spinal catheter. Br J Anesth 35:118-120, 1963

96. Waisman M, Schweppe Y: Postoperative cerebrospinal fluid leakage after lumbar spine operations. Conservative treatment. Spine 16:52-53, 1991

97. White JC, Hanelin J: Myelographic signs of brachial plexus avulsion. J Bone Joint Surg (Am) 36:113-118, 1954

98. Wilkinson HA: Nerve-root entrapment in "traumatic" extradural arachnoid cyst. J Bone Joint Surg (Am) 53:163-166, 1971

99. Wilson C, Jumar M: Traumatic spinal-pleural fistula. JAMA 179:812-813, 1962

100. Zide BM, Epstein FJ, Wisoff J: Optimal wound closure after tethered cord corrections. Technical note. J Neurosurg 74: 673-676, 1991

101. Zide BM, Wisoff JH, Epstein FJ: Closure of extensive and complicated laminectomy wounds. Operative technique. J Neurosurg 67:59-64, 1987

102. Zilkha A, Reiss J, Shulman K, et al: Traumatic subarachnoidmediastinal fistula; case report. J Neurosurg 32:473-475, 1970

Manuscript received May 22, 2000.

Accepted in final form June 8, 2000.

Address reprint requests to: Kee D. Kim, M.D., Department of Neurological Surgery 4860 Y Street, \#3740, Sacramento, California 95817.email: kdkim@ucdavis.edu. 